\title{
Educación deportiva \\ en la Educación Física escolar. \\ Un proceso de resistencia
}

\section{Sports education at school. A process of resistance}

\section{Mariana Sarni*}

\footnotetext{
* Doctora en Ciencias de la Actividad Física y el Deporte. Profesora adjunta del Departamento de Educación Física y Deporte del Instituto Superior de Educación Física de la Universidad de la República (Uruguay). Corresponsable del grupo de estudios Educación Física, Deporte y Enseñanza. •marianasarni@gmail.com https://orcid.org/0000-00029265-5658
}

\section{RECIBIDO: 30.8 .2021}

\section{Resumen}

El ensayo propone la educación deportiva como la orientación que debería ser privilegiada por el sistema educativo para la enseñanza del deporte en la Educación Física curricular. Comienza enunciando algunas ideas referidas a aspectos sociales, políticos y económicos que distinguen el estado actual del deporte moderno, a la vez que justifican su revisión crítica y esta orientación en particular, llegado el caso de establecer los sentidos, significados y la praxis de las enseñanzas del contenido deporte, tanto en los programas como en las clases del profesorado. Luego, partiendo de la idea de educación - y en consonancia con ella-, con base en trabajos de Velázquez Buendía, se trata la noción de educación deportiva y se enuncian los que a partir de ella deberían ser los contenidos de enseñanza del deporte en el área de la Educación Física curricular. Al cierre se manifiesta cómo la educación deportiva, como proceso de resistencia escolar, propiciaría la formación crítica y comprometida con el desarrollo de una cultura deportiva de los ciudadanos y las ciudadanas de un país, de acuerdo con los requerimientos y necesidades de las sociedades democráticas.

Palabras clave: educación física, deporte, enseñanza primaria. 


\section{Abstract}

The essay proposes Sports Education as the privileged orientation to be considered by the educational system for the teaching of sport in curricular Physical Education. It begins by enunciating some ideas referring to social, political and economic aspects that distinguish the current state of modern sport. A critical review and this specific orientation are justified, in order to establish the senses, meanings and praxis of the teaching contents, both in the syllabuses and in the teacher's classes. Then, starting from the idea of education -and in line with it- based on Velázquez Buendía (2001; 2004), the notion of Sports Education is dealt with, stating which should be the contents of the teaching of sports in curricular Physical Education. Finally, the essay shows how Sports Education, as a process of school resistance, would favor the development of a sports culture, with critical and committed citizens educated in accordance with the requirements and needs of democratic societies.

Keywords: physical education, sport, primary education

\section{Introducción}

El ensayo propone pensar la educación deportiva como la orientación privilegiada para abordar la enseñanza del deporte en la asignatura Educación Física en el contexto escolar. ${ }^{1}$

La afirmación encuentra justificación en las siguientes ideas centrales sobre los aspectos sociales, políticos y económicos distintivos del deporte moderno.

- El deporte abarca un espectro que va desde aquel centrado en el rendimiento y en el resultado (cuya máxima expresión es el deporte profesional) hasta aquel centrado en la recreación y en la participación. Ambas realidades responden a intereses de distinto tipo que, a su vez, condicionan la forma de entender el deporte y de practicarlo.

- Generalmente bajo su forma profesionalizada, que se está convirtiendo en hegemónica, constituye un agente de reproducción ideológica que tiende a mantener el orden social existente y a satisfacer determinados intereses sociales, políticos y económicos. ${ }^{2}$

1 Aclara de antemano que se la piensa como la orientación privilegiada para ser llevada a cabo por la educación física escolarizada, de forma secuenciada desde el primer ciclo escolar hasta enseñanza media inclusive.

2 Autores como Brohm (1982) y Bourdieu (1990), del campo de la sociología, Althusser (2005), del campo de la filosofía, o Velázquez Buendía (2004), Bracht y Caparroz (2009), Rozengardt (2011), Devís Devís 
- En ese extremo, surge el llamado deporte espectáculo, un producto de la modernidad que, sobre la base de una estructura política y económica dominante, ha transformado al deporte en mercancía y genera lógicas de consumo que sostienen intereses de mercado. Tales intereses se encuentran lejos de pensar en los sujetos y en una eventual democratización en cuanto al acceso a la práctica deportiva, y se deslizan imperceptiblemente como parte del currículo oculto de cualquier deporte que pretenda enseñarse. Por ello, la crítica dialéctica de esos mismos intereses será la base para enfrentar al deporte espectáculo con una eventual negación de sus formas, lo que habilitará entonces la promoción de un estado superior sostenido en la base de la educación deportiva.

- Al mismo tiempo, el deporte puede funcionar - y de hecho funciona-como un agente de transformación social que contribuye al cambio y a la superación de las injusticias y las desigualdades existentes, por lo que debe ser objeto de crítica ideológica. ${ }^{3}$ El docente, deliberadamente, habrá de preocuparse por generar contradicciones entre aquello que el deporte es y aquello que el deporte no es y podría ser, para permitir la puesta en marcha de mecanismos de confrontación y apropiación/transformación, cuestión central (en cuanto constitutiva) de una idea de educación.

- Dado que el deporte constituye un fenómeno sociocultural mundial de primer orden, es portador de intereses sociopolíticos y económicos, actúa como un agente de reproducción y transformación social, y tiene una gran presencia y capacidad de influencia en la vida de las personas. Desde el punto de vista de las sociedades democráticas, se hace necesario que los ciudadanos sean formados para ser capaces de actuar ante el fenómeno deportivo - entendido como práctica, como espectáculo y como objeto de consumo- de manera participativa, crítica y responsable.

Estas cuestiones justifican el (pre)ocuparse y considerar la educación deportiva escolar de las jóvenes generaciones no solo como un aspecto fundamental de su formación académica en el marco de la asignatura de Educación Física, sino como una necesidad fundamental de su formación como ciudadanos y ciudadanas, dada la influencia tan significativa que, de una u otra forma y con independencia de sus gustos y aficiones, va a ejercer el deporte sobre sus vidas.

(2018) y Sarni (2021), desde el campo de la educación física y el deporte, por citar algunos, sostienen un amplio debate que puede respaldar la afirmación realizada.

3 Entre los y las autoras más destacados que han venido sosteniendo estas ideas encontramos a la brasileña Carmen Soares (1996), al brasileño Valter Bracht y al español Roberto Velázquez Buendía. 


\section{Acerca de la educación: consideraciones básicas}

Hablar de educación implica, desde una perspectiva crítica, el compromiso de pensarla reflexionando los aspectos sociopolíticos e ideológicos que la configuran como práctica socialmente aceptada e históricamente construida, práctica cargada de significados, símbolos, valores y finalidades que la propia cultura le asigna, no siempre de manera consciente y manifiesta. Vale decir entonces que, como concepto, se ha venido definiendo y se seguirá definiendo de formas diversas, pero que, en cualquier caso, presupone

[...] de forma más o menos explícita, una concepción de la sociedad que se pretende mantener o construir y, por tanto, del sentido de la formación de que debe dotarse a los ciudadanos mediante la acción educativa para que tal proyecto pueda hacerse realidad. (Velázquez Buendía, 2000, p. 483)

En este mismo sentido se pronuncia Freire (1969), por ejemplo, cuando señala que la educación es praxis, reflexión y acción del hombre sobre el mundo para transformarlo.

En consecuencia, una educación que no ofrezca críticas sostenidas a la representación cultural (construida, generalmente impuesta y no natural), que no se enfrente con su contradicción deliberadamente, que no se proponga alterar la base objetiva e impulse un proceso contrahegemónico (atento) de transformación cultural (Gramsci, 2015) no podrá ser una verdadera educación, ni para la liberación individual ni para la construcción de una sociedad más libre, más igualitaria y más justa.

Una práctica educativa con interés emancipatorio es aquella en la que es el objeto el que cuestiona al propio objeto (Adorno, 2015), cuestionamiento que habilita la transformación. En ese recorrido, y particularmente en instituciones educativas ocupadas en la enseñanza, se asume la carga política subyacente de los objetos de enseñanza, los que, en tensión, han de pensarse desde el porqué y el para qué de su presencia y proyectarse su formación sobre una base de justicia social inmanente (Horkheimer, 2010).

La educación, superando la práctica de enseñanza, o, mejor dicho, (re)validando su valor epistémico en el marco de un proyecto educativo emancipatorio, de la mano de una idea de transformación cultural, se afirma como parte de la cultura -superestructura-, y se materializa en la realidad objetiva, en la praxis social. En este contexto, la escuela moderna, la escuela como hoy la conocemos, ha sido producto de innumerables críticas debido a su carácter esencialmente reproductivista. Sus formas se han vinculado en todo sentido y momento a la reproducción de relaciones orientadas a mantener las estructuras sociales originales, a la vez que se aleja de propuestas emancipatorias.

Quienes definen qué se hace, por qué y para qué se hace, qué se enseña, por qué y para qué se enseña en la escuela, son quienes controlan la educación y el sistema edu- 
cativo, los que, además, buscarán no alterar ciertas estructuras que para ellas son funcionales y fundamentales. La escuela, sus contenidos, sus estructuras y sus formas responden a alguna ideología dominante (Althusser, 2005) que se abocará a perpetuarse. En este sentido se pronuncia Bruner (1997, p. 47) cuando señala:

Las escuelas siempre han sido altamente selectivas en relación con los usos de la mente que cultivan: qué usos deben considerarse básicos, cuáles uniformes, cuáles son responsabilidad de la escuela y cuáles son responsabilidad de otros, cuáles son para las niñas y cuáles para los niños, cuáles para los niños de la clase obrera y cuáles para los superdotados. Sin duda, parte de esa selectividad estaba basada en las nociones que se tenían sobre lo que requería la sociedad o lo que necesitaba el individuo para salir adelante.

Podríamos afirmar de esta forma que las diferencias en las perspectivas educativas (y didácticas) estarán puestas en: a) si la educación limita al sujeto a simplemente reproducir(lo) o si, por el contrario, b) apuesta a mecanismos de liberación, para, en tensión interna, reproducir, producir y modificar esos rasgos culturales.

Tomando en consideración lo expuesto hasta aquí, esbozaremos la idea de educación que se asume en este trabajo, así como la finalidad o el propósito que debería tener la educación desde nuestro punto de vista, lo que más adelante permitirá presentar y sostener una idea y una finalidad de la educación deportiva.

Desde nuestra perspectiva, una educación para la transformación y el cambio social, emancipadora, es aquella que enfrenta los objetos de conocimiento a su propia contradicción, la que cuestiona aquellas verdades instaladas/naturalizadas para su eventual reconstrucción. Se trata, en definitiva, de aquella educación que se permite poner en cuestión todo objeto de enseñanza, para lo que se sirve de todas las partes que se seleccionan de la realidad -abstracciones-, lo que hará posible el análisis crítico de la realidad concreta, su (re)construcción y transformación.

Tal y como señala Freire (1969), la educación es -o, cabe añadir, debería serreflexión y acción sobre el mundo para transformarlo. En resumidas cuentas, desde el punto de vista adoptado, puede decirse, de manera muy sucinta y genérica, que la educación debe concebirse básicamente como un proceso intencional orientado a la adquisición y el desarrollo de conocimientos, capacidades y actitudes en los alumnos y alumnas, que, como señala Velázquez Buendía (2004) hagan posible e induzcan a las jóvenes generaciones a conducir su vida de manera autónoma y responsable, a beneficiarse y disfrutar de las posibilidades y los recursos culturales existentes (laborales, sociales, tecnológicos, recreativos, artísticos...), a participar e implicarse de manera activa, cons- 
tructiva y crítica en la conservación y el desarrollo de los valores, procedimientos y requerimientos de las sociedades democráticas, y a comprometerse y contribuir a que su funcionamiento sea acorde con tales principios, procedimientos y requerimientos.

\section{Educación deportiva:}

\section{concepto, características y finalidad 4}

Para Velázquez Buendía (2004), a quien seguiremos en esta parte de la exposición, el deporte puede ser considerado como un agente socializador, complejo, portador de intereses públicos y privados de muy distinto tipo, como una institución con lógicas e intereses propios, mundialmente desarrollada. Constituye, por tanto, un fenómeno social de tal magnitud que no puede, no debe ser obviado por los sistemas educativos. En efecto, la magnitud de su crecimiento en los procesos de globalización, su capacidad de reproducir y transmitir ideología, su potencial para la transformación y la mejora social, su diversificada y seductora oferta como objeto de consumo, su influencia en la vida de las personas, su potencial formativo, sus rasgos de legado cultural constituyen factores que, entre otros, generan la necesidad individual y social de que el campo del deporte sea considerado como un contenido de enseñanza y aprendizaje en el currículo escolar.

A diferencia de la conocida expresión deporte educativo (Le Boulch, 1991), noción fuertemente cuestionada por asumir equivocadamente que la práctica deportiva es en sí misma educativa, la educación deportiva presupone dar prioridad al propósito educativo que debe caracterizar y conducir el proceso de enseñanza deportiva en el marco del currículo escolar. Se trata de un planteamiento y de una idea de educación que habrá de reflexionarse mediada por los objetos y procesos de enseñanza del profesorado y por los objetos y procesos de aprendizaje del estudiantado, en la medida en que la enseñanza deportiva escolar pretenda propiciar, paralelamente, una mejora de la competencia motriz deportiva, una socialización crítica en la cultura deportiva y una transformación del deporte, entendido como fenómeno de alto contenido social y cultural.

En este sentido, Velázquez Buendía (2001) señala la importancia de precisar semánticamente la idea de educación deportiva, cuyo concepto incluye, o debería incluir, 
tanto finalidades de mejora de la competencia motriz deportiva como de desarrollo de las dimensiones afectivas, éticas y morales del sujeto, de su capacidad y sentido crítico, y de su compromiso con la transformación y la mejora de la cultura deportiva integrada en la sociedad de la que forma parte. Dicho autor señala, asimismo, que la idea de educación deportiva va más allá de las ideas de enseñanza deportiva y de iniciación deportiva, que tienden a centrarse y a situar su preocupación en la mera enseñanza y mejora de la competencia motriz deportiva, y, por otra parte, que la acción del profesorado debe orientarse de manera que los aprendizajes deportivos presupongan tal educación deportiva. Utilizando sus propias palabras (Velázquez Buendía, 2001, p. 69), en el proceso de educación deportiva:

la mediación docente tiene por objeto central contribuir a que los alumnos y las alumnas alcancen una autonomía intelectual, moral y social, mediante el desarrollo de sus capacidades cognitivas, motrices, de equilibrio personal, de inserción social y de relación interpersonal, al aplicar tales capacidades a la realización de aprendizajes de contenidos deportivos.

Así pues, de acuerdo con lo anterior, la idea de educación deportiva ha de presidir la planificación y los procesos de enseñanza y aprendizaje del deporte en la escuela -que, como objeto y bien cultural, constituye un contenido integrado en el currículo escolar (Sarni y Corbo, 2021)-, subordinando el planteamiento y el desarrollo de los contenidos deportivos a la intención educativa, que ha de manifestarse en los correspondientes planteamientos didácticos. En este sentido, tal orientación educativa aportará un valor añadido a la actuación y la responsabilidad docente en la temática, iluminando aspectos formativos que la expresión enseñanza deportiva, si no se circunscribe a esos lineamientos, puede llegar a desconocer, corriendo el riesgo de independizarse de ese marco de sentidos.

En resumidas cuentas, la idea de educación deportiva circunscribe la enseñanza deportiva que tiene lugar en el contexto escolar, planteada con una orientación prioritariamente educativa.

Así pues, en virtud de la idea de educación esbozada en el apartado anterior, es preciso cuestionar aquel deporte que se ha venido enseñando -y que incluso se sigue enseñando- como si su práctica y su existencia fueran algo natural y neutral desde el punto de vista ideológico, es decir, sin reflexión crítica: el deporte se enseña tal cual se observa, se piensa, se propone, se practica y se reproduce fuera de la escuela, ya sea bajo su orientación hegemónica de alto rendimiento o de la propiamente recreativa.

En este sentido, un desafío será problematizar la enseñanza deportiva, de manera que su finalidad se extienda a la formación de ciudadanos y ciudadanas como espectadores y como consumidores, unos y otras, de productos y servicios deportivos, con la 
crítica colectiva a la problemática como punto de partida de un proceso de transformación de la cultura del deporte, a partir de la reconstrucción del trabajo pedagógico de la Educación Física escolar.

Para este caso, Velázquez Buendía (2001, pp. 102-103) plantea que la enseñanza deportiva escolar, además de la dimensión de la práctica deportiva, debe tener en cuenta otras dos dimensiones formativas:

- la de espectadores e integrantes de un colectivo de espectadores que da sentido y significado al espectáculo deportivo;

- la de consumidores capaces de debatir su vínculo con aquellos servicios y productos del deporte pensados para su venta y consumo masivo.

Por otra parte, hablar de educación deportiva en la escuela debería suponer hablar de un tratamiento del deporte en clave de educación emancipatoria, en cuanto acción dialógica que supone atender a características distintivas de colaboración, unión, organización y síntesis cultural, superadoras de otras de conquista, división, manipulación e invasión cultural propias de la acción antidialógica, matrices antagónicas: la primera sirve a la liberación; la segunda, a la opresión (Freire, 1970). Las diversas maneras en las que se define (por el programa escolar y el docente que lo textualiza) el acercamiento/alejamiento del alumnado al hecho deportivo y a sus formas están determinadas, en gran parte, por el modo y el grado en que se tienen en cuenta las dimensiones señaladas en su enseñanza y en su propuesta educativa.

Si acordamos que la educación, desde una perspectiva crítico-emancipadora, se significa en una praxis liberadora, la educación que esta praxis reproduce dará lugar a aquella que habilita a los sujetos a un posicionamiento con clave política. Este tipo particular de educación es el encargado de poner a circular todos aquellos legados culturales que el proyecto político educativo considere necesarios para intervenir en determinado espacio social. Dada su actual inclusión en los diseños curriculares, el deporte, en cuanto se ha configurado como uno de los contenidos clave de la Educación Física de la escuela -hegemónico en muchos casos-, parece ser uno de esos legados.

La educación deportiva implicará, en definitiva, la formación de sujetos consumidores, espectadores y practicantes responsables del deporte que, a partir de un pensamiento y una actitud críticos, sean capaces de construir una visión y una actuación cada vez más autónoma, a partir del desmantelamiento de los sentidos y significados asignados tradicionalmente -y hegemónicamente- al deporte, a fin de (re)construirlos entre los propios sujetos, transformando al deporte y convirtiéndolo en un bien cultural que sea patrimonio de todos, incluidos aquellos a los que sus escasas capacidades cognitivomotrices les impiden destacarse en su práctica, y aquellos otros que, en función del lugar 
que ocupan en su espacio social, puedan parecer excluidos en virtud de un determinado capital económico, social o cultural (Bourdieu, 1998).

\section{Los contenidos de la enseñanza deportiva en el contexto escolar}

Tomando en consideración lo esbozado y en consonancia con lo expuesto, procede tratar a continuación cuáles deberían ser los contenidos del deporte abordado en la escuela, contenidos que responderían al propósito educativo, es decir, a la educación deportiva. Compartimos con Velázquez Buendía $(2001,2004)$ la idea de que para que un proceso de iniciación y enseñanza deportiva pueda integrar una dimensión educativa es preciso, por un lado, no limitarlo a la mejora de la competencia motriz deportiva, $y$, por otro, incluir de manera paralela en dicho proceso actividades y acciones orientadas a promover el desarrollo cognitivo, afectivo y moral del alumnado, que le permitan alcanzar mayores grados de autonomía y responsabilidad en su relación con el mundo del deporte a través de la problematización crítica de diferentes aspectos del fenómeno deportivo como objeto de saber.

\section{Contenidos vinculados a la formación como practicante del deporte}

Los contenidos u objetos de enseñanza deportiva, en este caso, estarían orientados a generar comportamientos autónomos, que habilitasen una práctica deportiva responsable, aportando un conocimiento acabado del deporte en torno a sus aspectos básicos de corte técnico, táctico y reglamentario, imprescindibles para permitir al escolar, a través de procesos de iniciación deportiva, ${ }^{5}$ incorporarse a la práctica del deporte en sus diversas formas y modalidades, ya sea de manera individual o colectiva. Así pues, la enseñanza de los deportes colectivos de balón, por poner un ejemplo, debería llevar al docente a proponer actividades -saberes enseñados- que reúnan las condiciones medulares del deporte colectivo de balón de que se trate, su lógica interna, tanto en un sentido

A este respecto, Velázquez Buendía (2001) cuestiona que el proceso de iniciación deportiva sea concebido únicamente, como concepto y como práctica, hacia el dominio del desempeño motor. Ello acaba clasificando los aprendices incluyéndolos o excluyéndolos del orden sociodeportivo. La iniciación deportiva debe concebirse como un proceso de incorporación a la lógica, los códigos y la manipulación de la cultura del juego. 
técnico como táctico. La enseñanza de este tipo de contenidos presupone que «La mejora de la competencia motriz constituye un fin que determina las decisiones sobre la selección de actividades de enseñanza y sobre el tipo de intervenciones docentes en la práctica» (Velázquez Buendía, 2001, p. 69). Se trataría, por tanto, de programar la enseñanza del deporte teniendo en cuenta la necesidad de condensar en las actividades sus principales aspectos estructurales, compañeros, adversarios, espacio, tiempo y reglamento (Parlebas, 2008), así como los principios del juego colectivo (Bayer, 1992), tanto los ofensivos - conservar la iniciativa, progresar hacia el objetivo y conseguir el objetivo- como, naturalmente, los defensivos - recuperar la iniciativa, impedir la progresión hacia el objetivo y proteger el objetivo-. Pero, además, el planteamiento y el desarrollo de tales actividades de enseñanza deberían estar orientados a que los alumnos y alumnas comprendan los problemas e identifiquen las demandas de las nuevas situaciones, lo que supondría que deberían ser capaces de «activar los recursos y conocimientos más apropiados para la acción, [...] comprender el significado y sentido de sus acciones y de lo que sucede en su contexto, y [...] reflexionar sobre los resultados de tales acciones aprendiendo de ellas» (Velázquez Buendía, 2004, p. 181).

De manera paralela, los contenidos y actividades que propician el desarrollo de la competencia motriz deportiva deben ir acompañados de otro tipo de contenidos y actividades de enseñanza que vehiculicen aspectos referidos a la formación cognitiva, actitudinal y moral. Así, por ejemplo, para el tratamiento de la noción de deporte deberá considerarse la exclusión que acompaña su práctica, especialmente cuando se orienta al rendimiento, a fin de recuperar críticamente valores inclusivos que el mismo objeto posee, desde los saludables hasta los placenteros. En lo relativo al significado y el valor de la competición y del resultado, su planteamiento deberá hacer notar el significado y el valor de la participación, de la colaboración y del bienestar personal. En lo que tiene que ver con el significado y el sentido de las reglas, y del adversario como compañero de juego, no cabe sino impulsar la asunción del deber de respetar y del derecho a ser respetado. Si se tratase de lo que atañe a los efectos de la práctica deportiva en la salud, se hace imprescindible conocer y analizar los requisitos para que la práctica del deporte sea efectivamente saludable (Velázquez Buendía, 2004, p. 188).

\section{Contenidos vinculados a la formación como espectador de competiciones y espectáculos deportivos}

Una orientación educativa de los contenidos de la enseñanza deportiva debería tener presente tanto la figura del sujeto en cuanto integrante del colectivo de espectadores como la del espectador aislado que, desdoblándose, otorga sentido y significado al espectáculo deportivo (Velázquez Buendía, 2001, 2004). 
En el primer caso, la educación deportiva debería propiciar que el alumnado, como espectador, llegue a ser capaz de, entre otras cosas, presenciar el espectáculo deportivo con pleno conocimiento de las reglas que rigen el deporte en cuestión, de valorar la dificultad y la complejidad de las acciones técnico-tácticas que tienen lugar en el terreno de juego, de rechazar las conductas poco éticas o violentas de los jugadores o jugadoras del propio equipo y del equipo adversario, y de reconocer y aprobar sus conductas deportivas y su esfuerzo personal, así como de relativizar la importancia del éxito y de la derrota. En este sentido, la formación como espectador requiere generar intencionalmente $-\mathrm{y}$ tener presente de manera constante- espacios formativos en los que los alumnos y alumnas valoren la importancia social, moral y personal de actuar críticamente ante el espectáculo deportivo, siendo conscientes del costo personal que representa el sumarse a comportamientos catárticos inadecuados para sí y para otros. Ello implica profundizar en la importancia y la necesidad de afrontar la contemplación de los espectáculos deportivos con criterios propios que permitan enjuiciar críticamente los desmanes que en ellos pudieran producirse, los que provienen a menudo incluso de fuera del deporte. Esta situación requiere develar y poner frente al estudiantado los posibles intereses extradeportivos que pueden filtrarse en el espectáculo, propios de los agentes que lo organizan y regulan, quienes suelen torcer lo que allí sucede para su beneficio. Esto supone formar espectadores críticos y atentos a revisar e incidir en el debate de lo aparentemente natural, cuestionando el poder simbólico de lo que es en definitiva un espectáculo deportivo (Velázquez Buendía, 2004).

En el segundo caso, considerando ahora a los alumnos y alumnas como integrantes del colectivo de seguidores afines a uno u otro equipo o deportista que se manifiestan en el marco del espectáculo deportivo, la educación deportiva debería propiciar la adquisición de actitudes autónomas y responsables que, aun en el calor del juego e incluso en situaciones de resultados deportivos adversos, den lugar a conductas comedidas, basadas en el respeto al árbitro y a los rivales, rechazando las conductas ofensivas y agresivas de otros espectadores hacia el árbitro o hacia los jugadores rivales (Velázquez Buendía, 2004). Se trata, en este sentido, de trabajar con alumnos y alumnas para que puedan dar sentido y significado a su lugar como aficionado deportivo, de manera que sean capaces de distinguir entre lo que es unificarse para alentar colectivamente a su equipo y lo que es perderse en ánimos y pasiones colectivos que gradualmente puedan ir subsumiendo su individualidad en una suerte de persona-masa, lo que implica el riesgo de acabar perdiendo su identidad. Tales búsquedas didácticas y sus resultados supondrán para el docente la instalación en clase de contenidos de enseñanza cuyo planteamiento y desarrollo tienda, intencionalmente, a favorecer en el alumnado la adquisición del conocimiento y de la capacidad de identificación y de análisis crítico y autónomo de aquellos aspectos positivos y negativos que se evidencian en el espectáculo 
deportivo (tensión placer/displacer, violencia, fair play, manejo tendencioso de la regla, esfuerzo, generosidad, picaresca...).

En resumidas cuentas, la idea de educación deportiva debe incluir la educación como contemplador de espectáculos deportivos, y desafía al profesorado a la búsqueda intencional de contenidos de enseñanza que persigan propósitos específicos de formación para que el alumnado pueda asumir un lugar moral y crítico en la construcción y la manifestación del deporte y del espectáculo deportivo. El planteamiento y el desarrollo de tales contenidos presupone la realización de actividades tales como reflexiones sobre el significado y el sentido de las reglas de juego; análisis crítico de posturas, conductas y actitudes específicas inadecuadas que tienen lugar durante el espectáculo deportivo; identificación y valoración de los intereses extradeportivos que, en un momento determinado, pueden condicionar la práctica y el espectáculo deportivo y que, en ocasiones, subordinan lo que sucede en el juego a la consecución de intereses espurios; revisión de los excesos simbólicos del espectáculo deportivo que llevan a concebir la ganancia o la pérdida de un partido como una ganancia o pérdida del honor, de la masculinidad, del prestigio nacional...

\section{Contenidos vinculados a la formación}

\section{como consumidor de productos y servicios deportivos}

En el marco de la sociedad de consumo, la educación deportiva debe promover la discusión del vínculo de los ciudadanos y ciudadanas, como consumidores, con los servicios y productos del deporte, ofertados generalmente de forma muy atractiva y frecuentemente pensados para su venta masiva, cuyo consumo constante y acrítico perpetúa y satisface los intereses económicos de los propietarios de los medios de producción (Velázquez Buendía, 2001).

El deporte como construcción social e integrado a las dinámicas productivas se produce y reproduce, y produce además a su consumidor, es decir, genera necesidades de consumo que promueven la circulación de capitales (Marx, trad. 2008).

Parece claro que el espectáculo deportivo hoy en día promueve una industria de enorme relevancia a escala mundial, con cuantiosos beneficios económicos, causante en muchos casos de la modificación de las lógicas internas y directrices del mismo deporte (tácticas, reglas, número de jugadores, períodos de descanso, vestimenta, nuevos gestos 
deportivos, etcétera), con el fin de hacerlo más atractivo para los espectadores/consumidores. ${ }^{6}$

Todo esto lleva a pensar que la educación física, más concretamente la educación deportiva, habría de ocuparse, entre otras cosas, de problematizar la relación entre los ciudadanos y ciudadanas, por un lado, y las prácticas consumistas en el deporte, por el otro, para lo que se han de instalar en la escuela las necesarias revisiones de la problemática enunciada. La educación deportiva tendría, por tanto, que ocuparse de poner en práctica actividades de enseñanza que, por ejemplo, propongan develar ante los ojos del alumnado cuestiones como las estrategias y prácticas de quienes poseen los medios de producción, capaces de propiciar e instalar una necesidad para a partir de allí desplegar toda clase de productos y servicios tendentes a satisfacerla, poniendo en marcha y realimentando el mercado de consumo. En este sentido se pronuncia Bourdieu (1990, pp. 212-213) cuando señala:

Las transformaciones de la demanda son una dimensión de la transformación de los estilos de vida y obedecen a reglas generales. La correspondencia que vemos entre ambas series de transformaciones se debe sin duda, como en otros casos, a que el espacio de los productores (es decir, el campo de los agentes e instituciones que son capaces de transformar la oferta) tiende a reproducir en sus divisiones las del espacio de los consumidores.

Ejemplos de este escenario contemporáneo sobran: el tratamiento televisivo que se da al deporte (particularmente al deporte profesional) en espacios centrales de todos los canales y su abordaje en materia de lo bueno y lo malo; las vidrieras y escaparates de los comercios que asocian a los ídolos deportivos (generalmente masculinos) con un sinfín de productos (ropa, higiene, perfume...) que tienden a confundir medios con fines y a asimilar el tener con el ser; productos de alimentación que parecen instalar en quienes los ingieren una suerte de encantamiento mágico propio de un estado de conciencia que debimos haber abandonado en la prehistoria; la prioridad publicitaria que se da a los efectos estéticos de las prendas deportivas con respecto a su calidad, a su adecuación y funcionalidad e incluso a la relación calidad-precio.

La educación deportiva, en suma, deberá proponer actividades que, a través del análisis y la reflexión crítica del alumnado, tomando en consideración las características y necesidades de cada tramo de edad, hagan posible, entre otras cosas: el consumo de

Este impacto se advierte en un crecimiento académico exponencial de los estudios e investigaciones realizados en el ámbito de las ciencias que sustentan y estudian el deporte (medicina, nutrición, economía, psicología, comunicación, etcétera), enfocadas hacia la mejora de la eficiencia deportiva y de los resultados económicos, en desmedro del estudio y el financiamiento de la investigación de corte pedagógico y social. 
productos y servicios deportivos ajustados y adecuados a las necesidades reales y con razonable relación calidad-precio; la problematización del mercado deportivo y sus ofertas publicitarias, cuando no propagandísticas; la valoración de la oferta de productos y servicios deportivos en términos económicos, de utilidad y necesidad personal y social, de explotación destructiva del medio ambiente, de proximidad a los ciudadanos...; el análisis de la comunicación publicitaria y de sus estrategias para inducir a los ciudadanos y ciudadanas a seguir las modas y a consumir productos deportivos que no responden a una necesidad anterior; el empoderamiento sobre los derechos del consumo y del usuario del deporte.

\section{Contenidos vinculados a la formación}

\section{como ciudadano crítico que participa y contribuye \\ a la conformación de la cultura deportiva}

Este tipo de contenidos incluye los ya expuestos, a los que trasciende en un sentido global e integrador, de manera que, a través de las correspondientes actividades de enseñanza y aprendizaje, vayan desarrollando las capacidades y actitudes de los alumnos y alumnas que les permitirán conducirse en el futuro como ciudadanos y ciudadanas con sentido crítico, participativo y responsable, que demandan la construcción de una cultura deportiva acorde con las características, los requerimientos y las necesidades de las sociedades democráticas y tratan de contribuir a ello (Velázquez Buendía, 2004).

Se trata, en definitiva, de tener presente que el deporte, en cuanto construcción sociocultural, conlleva en su matriz intereses político-económicos no siempre acordes con las necesidades y los principios que fundamentan las sociedades democráticas, por lo que han de ser desmantelados, contradichos y (re)construidos a fin de ir promoviendo entre el alumnado la formación de estados de conciencia políticos y la participación en acciones consecuentes a favor de un proyecto colectivo ciudadano. Ello supone, entre otras cosas, anticiparse a la presión de quienes intentarán mantener y desarrollar el deporte y la cultura deportiva a favor de sus propios intereses, sean estos políticos, económicos o ideológicos.

Como un tramo (significativo) de un saber social, integrar este tipo de contenidos de enseñanza en la escolaridad (ni más ni menos) ha de ser parte de un proyecto de formación de un ciudadano o ciudadana que, como sujeto de esa sociedad y participante crítico de su aprendizaje en la escuela, llegue a ser capaz de valorar y transformar su cultura (deportiva) y de someter a la crítica política, en el caso que nos ocupa, el bien común que pudieran ofrecer la educación física en general y el deporte en particular. 
Entre estos contenidos, señala Velázquez Buendía (2004), han de proyectarse actividades de enseñanza que, entre otras posibilidades, habiliten oportunidades para manifestarse públicamente ante acciones ilegítimas del deporte o conductas antideportivas en eventos deportivos; propicien espacios de colaboración social en materia barrial, zonal o comunal que enaltezcan aspectos formativos del deporte; generen lugares o momentos concretos de trabajo en el aula o fuera de ella que promuevan la reflexión sobre el deporte como construcción social, sujeta a intereses humanos diversos y muy frecuentemente ocultos detrás de los grandes capitales mundiales. Si bien el deporte, como señala Velázquez Buendía (2001, p. 71), «puede contribuir a reproducir y transmitir los valores, estructuras, estereotipos, jerarquías, significados [...] que contiene en su seno, que lo caracterizan y que no son sino una réplica de los que imperan en la sociedad, favoreciendo con ello la legitimación ideológica del orden social existente», también contiene, como señala este mismo autor, un importante potencial para la transformación del orden establecido hacia la consecución de mayores niveles de justicia, igualdad, bienestar y prosperidad social.

\section{A modo de cierre}

El fenómeno de la globalización ha transformado al deporte en patrimonio de la humanidad, de modo que puede considerarse como un bien cultural, lo que le confiere un valor intrínseco. Desde esta perspectiva, todos los sujetos, en igualdad de condiciones, deberían poder acceder a él como practicantes y como espectadores, al margen de su mayor o menor competencia motriz.

Su enseñanza como contenido curricular debería llevarse a cabo con un enfoque estrictamente educativo, que contemple las diversas formas en que las personas participan en él como fenómeno social y cultural, que trascienda la propia práctica deportiva -el juego deportivo como representación hegemónica en las escuelas-y tome en consideración, además de la educación como practicante de deporte, otros aspectos, como pueden ser la educación como espectador deportivo y la educación como consumidor de productos del propio deporte.

Ello propiciaría la formación de ciudadanos y ciudadanas participativos, críticos y comprometidos con el desarrollo de una cultura deportiva acorde con los requerimientos y necesidades de las sociedades democráticas.

En esa dirección deberían plantearse el sentido y el significado de la enseñanza deportiva en el contexto escolar, y ese sentido y significado deberían constituir la principal justificación de la introducción del deporte como contenido de enseñanza y aprendizaje en el currículo escolar. 


\section{Referencias bibliográficas}

Adorno, T. W. (2015). Filosofía y sociología. Buenos Aires: Eterna Cadencia.

Aisenstein, A. (2007). La enseñanza del deporte en la escuela. Buenos Aires: Miño y Dávila.

Aisenstein, A. (2008). Deporte en la escuela. ¿Vale la pena? En C. Torres (ed.), Niñez, deporte y actividad física: Reflexiones sobre una relación compleja (pp. 119-134). Buenos Aires: Miño y Dávila.

Aisestein, A. (2009). La enseñanza escolar de la educación física y el deporte. En R. Gómez y L. Martínez (coords.), La educación física y el deporte en edad escolar: El giro reflexivo en la enseñanza. Buenos Aires: Miño y Dávila.

Althusser, L. (2005). La filosofía como arma de la revolución. México: Siglo XXI.

Bayer, C. (1992). La enseñanza de los juegos deportivos colectivos. Barcelona: Hispanoeuropea.

Bourdieu, P. (1990). Sociología y cultura. Ciudad de México: Grijalbo.

Bourdieu, P. (1998). Capital cultural, escuela y espacio social. México: Siglo XXI.

Bracht, V., y Caparroz, F. E. (2009). El deporte como contenido de la educación física escolar: La perspectiva crítica de la educación física brasileña. En R. Gómez y L. Martínez (coords.), La educación física y el deporte en edad escolar: El giro reflexivo en la enseñanza. Buenos Aires: Miño y Dávila

Brohm, J. (1982). Sociología política del deporte. México: Fondo de Cultura Económica.

Bruner, J. (1997). La educación, puerta de la cultura. Madrid: Machado.

Colectivo de autores. (1991). Metodologia do ensino da educação física. Porto Alegre: Cortez.

Devís Devís, J. (2018). Los discursos sobre las funciones de la educación física escolar: Continuidades, discontinuidades y retos. Revista Española de Educación Física y Deportes, (423), 121-131.

Freire, P. (1969). Educación como práctica de la libertad. (36. ed.). Madrid: Siglo XXI.

Freire, P. (1970). Pedagogía del oprimido. (35. a ed.). Madrid: Siglo XXI.

Gramsci, A. (2015). Antología. México: Siglo XXI.

Horkheimer, M. (2010). Crítica de la razón instrumental. Madrid: Morata.

Le Boulch, J. (1991). El deporte educativo: Psicocinética y aprendizaje motor. Barcelona: Paidós.

Manzino, C., y Rodríguez, V. (2015). El deporte escolar y sus competiciones en el ámbito público. Montevideo: ISEF. Recuperado de https://encuentro2020.isef.edu.uy /img/deporte\%20escolar\%20y\%20sus\%20competiciones.pdf.

Manzino, C., Sarni, M., Noble, J., Suburú, A., Ruga, M., y Cardozo, J. (2017). Deporte escolar. En A. Craviotto, Educación física y escuela: Revisión y actualización de saberes (pp. 42-60). Montevideo: Universidad de la República. 
Marx, K. (2008). Contribución a la crítica de la economía política. México: Siglo XXI. Parlebas, P. (2008). Elementos de la sociología del deporte. Barcelona: Paidotribo. Ron, O. (2015). Deporte, deportes. En C. Carballo (dir.), Diccionario crítico de la educación física académica: Rastreo y análisis de los debates y tensiones del campo académico de la educación física en Argentina (pp. 121-126). Buenos Aires: Prometeo Libros.

Ron, O., y Fridman, J. (2019). La educación física en la escuela y su enseñanza: Homogeneidades, diversidades y particularidades. La Plata: Universidad Nacional de la Plata. Recuperado de https://www.libros.fahce.unlp.edu.ar/index.php/libros/catalog/book/135.

Rozengart, R. (2011). Una mirada pedagógica al deporte. EFDeportes, 15(154). Recuperado de https://www.efdeportes.com/efd154/una-mirada-pedagogica-al-deporte.htm.

Sarni, M. (2018a). Deporte, enseñanza y curriculum. Borradores, 1(1), 32.

Sarni, M. (2018b). Educación física, método y deporte en el sistema educativo. Borradores, 1(2), 3-13.

Sarni, M. (2018c). Panorama de la enseñanza de la educación física en Uruguay. En J. Leymonié (coord.), Prácticas docentes en educación física: Una mirada innovadora (pp. 27-62). Montevideo: Grupo Magró. (Serie Educación CLAEH, 2).

Sarni, M. (2021). La enseñanza deportiva en las escuelas públicas de Uruguay: La normativa curricular y las creencias y prácticas docentes. Madrid: UAM.

Sarni, M., y Corbo, J. L. (2018). Las testificaciones en educación física, ¿un lugar para aprender? EmásF, Revista digital de Educación Física, 10(55), 22-32. Recuperado de https://emasf.webcindario.com/Las_testificaciones_en_la_EF_escolar_una_ oportunidad_para_aprender.pdf.

Sarni, M., y Corbo, J. L. (2021). El sentido del contenido deporte en el programa de educación primaria (Uruguay). Revista Universitaria de la Educación Física y el Deporte, 1(14). Recuperado de http://www.revistasiuacj.edu.uy/index.php /rev1/article/view/181.

Sarni, M., y Noble, J. (2018). Deporte y enseñanza: Estudios desde el propio campo. En B. Mora (coord.), Encontrando el futuro de los estudios sociales y culturales sobre deporte. Montevideo: Tradinco.

Sarni, M., y Noble, J. (comp.). (2019). Del deporte y su enseñanza. Montevideo: Ediciones Universitarias. Recuperado de https://hdl.handle.net/20.500.12008/21897.

Sarni, M., y Noble, J. (comps.). (2021). Educación física, deporte y enseñanza: Aportes a su reflexión. Instituto Superior de Educación Física. Montevideo: Ediciones Universitarias.

Soares, C. L. (1996). Educação fisica escolar: Conhecimento e especificidade. Revista Paulista Educação Fisica, (2), 6-12. 
Velázquez Buendía, R. (2000). ¿Existe el deporte educativo? Un ensayo en torno a la naturaleza educativa del deporte. En O. R. Contreras Jordán (coord.), Actas del XVIII Congreso Nacional de Educación Física (pp. 481-492). Cuenca: Universidad de Castilla la Mancha.

Velázquez Buendía, R. (2001). El currículo de la educación física a debate. En Deporte: ¿presencia o negación curricular? Actas del XIX Congreso Nacional de Educación Física de Facultades de Educación (pp. 65-104). Murcia: Servicio de Publicaciones de la Universidad de Murcia.

Velázquez Buendía, R. (2004). Enseñanza deportiva escolar y educación. En A. Fraile y J. L. Hernández (coord.), Didáctica de la educación física: Una perspectiva crítica y transversal (pp. 171-196). Madrid: Biblioteca Nueva. 